\title{
Prolonged air leak: Another instance where time is money
}

\author{
Matthew J. Bott, MD
}

From the Thoracic Service, Department of Surgery, Memorial Sloan Kettering Cancer Center, New York, NY. Disclosures: Author has nothing to disclose with regard to commercial support.

Received for publication May 10, 2018; revisions received May 10, 2018; accepted for publication May 10, 2018; available ahead of print July 17, 2018.

Address for reprints: Matthew J. Bott, MD, Thoracic Service, Department of Surgery, Memorial Sloan Kettering Cancer Center, 1275 York Ave, New York, NY 10065 (E-mail: bottm@mskcc.org).

J Thorac Cardiovasc Surg 2018;156:1222-3

$0022-5223 / \$ 36.00$

Copyright (c) 2018 by The American Association for Thoracic Surgery

https://doi.org/10.1016/j.jtcvs.2018.05.032

In their study, Brunelli and colleagues sought to financially validate the European Society of Thoracic Surgeons (ESTS) risk score for predicting prolonged air leak (PAL) after video-assisted thoracic surgery lobectomy. ${ }^{1}$ Length of hospital stay was previously shown to be 3 days longer for highrisk than low-risk patients. ${ }^{2}$ Although this implied financial consequences for surgery on high-risk patients, a formal financial analysis was not possible because of the multiinstitutional nature of that study. Addressing this knowledge gap, Brunelli and colleagues ${ }^{1}$ applied the ESTS risk score model to a cohort of patients from the authors' institution for whom granular cost data could be analyzed, concluding that postoperative costs are indeed higher in patients in the higher ESTS risk classes, even those who do not have PAL.

The risk score itself is notable for its relative simplicity and ease of use. The model assigns points on the basis of 3 weighted variables: male sex (1 point), forced expiratory volume in 1 second $<80 \%$ of predicted (1 point), and body mass index $<18.5$ ( 2 points). Classes are defined according to increasing risk of PAL, as follows: A (0 points) $6.3 \%, \mathrm{~B}$ (1 point) $10 \%, \mathrm{C}$ ( 2 points) $13 \%, \mathrm{D}$ ( $>2$ points) $25 \%$. Classes $\mathrm{C}$ and $\mathrm{D}$ would generally be considered high risk according to the authors. Whereas this simplicity is a major strength, it does comes at a cost to the score's ability to discriminate patients into classes. For instance, of 353 patients analyzed in the current study, $81 \%$ fit the criteria for class A or B (low risk), with $<3 \%$ in the highest-risk group (class D). Similarly, the class-specific incidence of PAL in this cohort differed from that reported in the original series.

Nonetheless, the authors performed a thorough financial analysis that included fixed and variable inpatient postoperative costs for each patient. Postoperative costs were approximately $\$ 2000$ higher for high-risk (ESTS class C or D) than low-risk patients. The main driver of this appears to be prolonged hospital stay (approximately 2 days longer); costs were also higher in high-risk patients without PAL (approximately $\$ 600$ higher). Most patients with PAL $(84 \%)$ were discharged home with a portable chest drain in place, suggesting costs for these patients might have been substantially higher if they had been hospitalized until chest

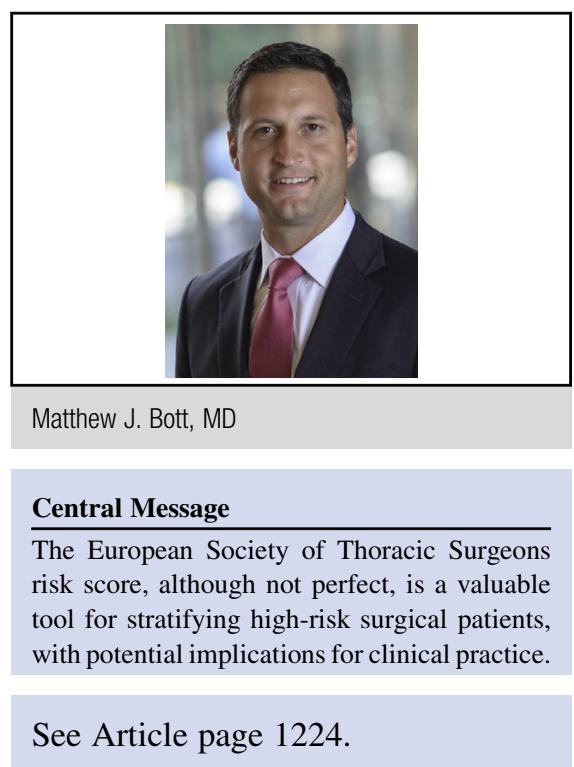

tube removal. Similarly, the analysis also does not factor in treatment costs after discharge (eg, home care, readmissions), which could further increase costs for high-risk patients.

The authors later suggest that the ESTS risk score might be used to select patients for intraoperative techniques and postoperative care pathways designed to minimize PAL and/or lessen its effects. Whereas fast-track recovery pathways with low thresholds for discharge with domiciliary drains seem reasonable, other strategies, such as routine use of lung sealants in high-risk patients, likely require further study (the authors do note that the benefit of such sealants in reducing hospital stay has not been consistently reported). ${ }^{3,4}$ Similarly, the discriminatory power of the ESTS score itself might pose challenges for patient selection. For instance, all male patients with a forced expiratory volume in 1 second $<80 \%$ would be considered high risk (class $\mathrm{C}$ ), and these patients make up a substantial proportion of the surgical population at many institutions.

In summary, the authors should be commended on an excellent study that further emphasizes the social and financial burden PAL places on our patients and their families. Additional efforts to minimize these complications will yield substantial dividends to patients and payors alike.

\section{References}

1. Brunelli A, Pompili C, Dinesh P, Bassi V, Imperatori A. Financial validation of the European Society of Thoracic Surgeons risk score predicting prolonged air leak following VATS lobectomy. J Thorac Cardiovasc Surg. 2018;156:1224-30. 
2. Pompili C, Falcoz PE, Salati M, Szanto Z, Brunelli A. A risk score to predict the incidence of prolonged air leak after video-assisted thoracoscopic lobectomy: an analysis from the European Society of Thoracic Surgeons database. J Thorac Cardiovasc Surg. 2017;153:957-65.

3. Zaraca F, Vaccarili M, Zaccagna G, Maniscalco P, Dolci G, Feil B, et al. Cost-effectiveness analysis of sealant impact in management of moderate in- traoperative alveolar air leaks during video-assisted thoracoscopic surgery lobectomy: a multicentre randomised controlled trial. J Thorac Dis. 2017;9: 5230-8.

4. Malapert G, Hanna HA, Pages PB, Bernard A. Surgical sealant for the prevention of prolonged air leak after lung resection: meta-analysis. Ann Thorac Surg. 2010; 90:1779-85. 